\title{
Study of Silent Myocardial Infarction in Type Two Diabetes Mellitus Patients in a Tertiary Care Center
}

\author{
Abhijit Arvind Patill1, Makrand Mane², Vivek Redkar³ \\ 1, 2, 3 Department of Medicine, Krishna Institute of Medical Sciences, (Deemed to Be University), \\ Karad, Maharashtra, India.
}

\section{ABSTRACT}

\section{BACKGROUND}

Coronary artery disease is known as a serious plague because of its regularity in different bits of the world. The signs of coronary artery issue handle a wide range from the mind boggling minor coronary atherosclerosis without angina or ischaemia to sudden passing

\section{METHODS}

The present study was cross sectional, observational study carried out at tertiary care center. This study was conducted during the period from January 2016 to June 2017. All Type two Diabetes Mellitus 100 patients attending Department of Medicine included in the study.

\section{RESULTS}

Majority of study subjects were in age 51 - 60 years (46\%) having DM (Diabetes Mellitus) since 5 - 10 years ( $46 \%$ ). A lot of patients overweight ( $40 \%$ ), dyslipidaemia $(22 \%)$. It mean fasting and post prandial glucose among patients was $164 \pm 15.18$ $\mathrm{mg} / \mathrm{dL}$ and $189.4 \pm 23.29 \mathrm{mg} / \mathrm{dL}$ exclusively. The mean LDL, HDL, VLDL, complete cholesterol and greasy oils levels among patients was $118.14 \pm 24.2 \mathrm{mg} / \mathrm{dL}, 42.60 \pm$ $5.12 \mathrm{mg} / \mathrm{dL}, 35.68 \pm 7.09 \mathrm{mg} / \mathrm{dL}, 204.96 \pm 28.76 \mathrm{mg} / \mathrm{dL}, 166.17 \pm 31.92 \mathrm{mg} / \mathrm{dL}$ independently. The regularity was $27 \%$. The prevalence of MI among DM patients was major in age pack 51 - 60 years (13\%). The ECG changes in calm MI among DM patients showed that a lot of calm MI patients had ST dejection and adjusted T wave inversion (77.77).

\section{CONCLUSIONS}

Standard checking ECG is be commonly useful and unobtrusive gadget in myocardial ischaemia area $\mathrm{n}$ asymptomatic diabetic patients
Corresponding Author: Dr. Makrand Mane,

Department of Medicine, Krishna Institute of Medical Sciences, (Deemed to Be University), Karad, Maharashtra, India. E-mail: makarand.mane@gmail.com

DOI: $10.14260 / \mathrm{jemds} / 2020 / 726$

How to Cite This Article:

Patil AA, Mane M, Redkar V, et al. Study of silent myocardial infarction in type two diabetes mellitus patients in a tertiary care center. J Evolution Med Dent Sci 2020;9(44):3305-3309, DOI: $10.14260 /$ jemds $/ 2020 / 726$

Submission 04-06-2020,

Peer Review 24-09-2020,

Acceptance 30-09-2020,

Published 00-11-2020.

Copyright (C) 2020 Abhijit Arvind Patil et al. This is an open access article distributed under Creative Commons Attribution License [Attribution 4.0 International (CC $B Y$ 4.0)]

\section{KEY WORDS}

Myocardial Ischaemia, Diabetes Mellitus. 


\section{BACKGROUND}

Coronary artery disease has become a major health problem throughout the world. The signs of coronary artery vary from being a minor coronary atherosclerosis without angina or ischaemia to sudden passing. Investigates all through the past very few decades provoked the possibility of evasion, clinical organization and cautious myocardial revascularization and besides to the regard for asymptomatic coronary passageway sickness and calm myocardial ischaemia. ${ }^{1}$

Silent myocardial ischaemia is described as angina. In study, $30 \%$ of myocardial infarcts hushed up, examined unmistakably by consecutive electrocardiography. 2,3 Cardiovascular diseases and particularly coronary issue are the fundamental wellsprings of death with type-2 diabetes $\cdot 4,5$ CHD (Coronary Heart Disease) is dependably asymptomatic in these patients, and is thusly at a pushed stage when it ends up being clinically appear.6,7 Consequently, most standards propose a deliberate screening by pressure testing of asymptomatic high risk patients with diabetes. 8,9

The prevalence of diabetes mellitus is truly broadening. More than 170 million patients have DM wherever all through the world, and the World Health Organization (WHO) guess broadens double a similar number of patients in $2025 \mathrm{DM}$ is a huge cardiovascular risk factor, and it habitually prompts genuine cardiovascular challenges (periphery artery sickness, myocardial confined rot, stroke). Coronary course disease is the basic driver of death with DM and records for over $75 \%$ of deaths. Silent myocardial ischaemia is progressively increasing in diabetic patients inciting a conceded finding and a further evolved period of the CAD (Coronary Artery Disease) at the hour of the end.[10] Diabetic patients intertwine a particularly high-danger pack for coming about cardiovascular events, with a partiality for calm myocardial ischaemia. ${ }^{11}$ In one appraisal, $12 \%$ of diabetic patients had calm ischaemia, while $19 \%$ of relative patients had beguiling ischaemia. ${ }^{12}$ Truth be told, there is creating assertion that asymptomatic myocardial regions of kept degradation and calm ischaemia happen fundamentally more occasionally in diabetic patients. ${ }^{13}$ The parts for diminished angina in this get-together of patients harden moving torment limit affectability, autonomic neuropathy, and mental factors. ${ }^{14}$ For any circumstance, whether or not the region of calm ischaemia recorded during a tiny bit at a time life fuses a self-supervising hazard factor for mortality remains cloud. The deterrent for screening diabetic patients depends essentially on whether the isolating affirmation of coronary easily course contamination would recognize therapeutic approaches that would reduce heart wretchedness and mortality. Clinical conditions that may warrant screening in asymptomatic patients consolidate preoperative open entryway for major no cardiac or vascular surgery, 15 screening before renal transplantation, ${ }^{16}$ and evaluation before starting a staggering movement program..$^{17}$ The most recent guidelines released by American Heart Association favour non-invasive testing inside seeing a high-chance cautious action, or a transitional risk action joined with poor utilitarian cut off regarding moreover chance depiction before clinical method, even without symptoms. ${ }^{18}$ The headway in area and treatment of CAD grants us to reconsider the screening of SMI (Silent Myocardial Ischaemia), with the craving for an early CAD assurance, which will provoke a dynamically fruitful treatment and the decrease of cardiovascular disarrays and mortality. Hence, the present study conducted to study silent myocardial ischaemia / infarction in type 2 diabetes mellitus patients.

\section{METHODS}

After obtaining Institutional Ethical Committee clearance, this cross-sectional study was conducted over a period of two years at a tertiary care centre. 100 type 2 diabetes mellitus patients were selected by simple random sampling technique.

\section{Sample Size Estimation}

The power of silent MI in DM was taken as $30 \%$. Sample size was evaluated at $5 \%$ level of importance with an acceptable error of $10 \%$ and a model size of 100 cases.

\section{Inclusion Criteria}

Patients with type 2 diabetes mellitus with $>1$-year range who do not have any cardiovascular related symptoms and above the age of 18 years.

\section{Data Collection}

Cases were selected from the Department of Medicine [OPD (Out Patient Department) and IPD (In Patient Department)], Krishna Institute of Medical Sciences, Karad. Informed consent was obtained from all the patients they were assessed with separate history, clinical evaluation and relevant assessments including resting ECG. Each subject was allowed to rest in prostrate position for 15 minutes before ECG recording is done. Following the standard procedure, 12 lead ECG was recorded and evaluated. BMI was calculated for all the patients. BMI classification by National Heart, Lung and Blood Institute, U.S. Department of Health \& Human Services was used $^{10}$. After period of rest, pulse rate and blood pressure were measured.

\author{
Investigations Done \\ 1. FBSL / PPBSL / HbA1C \\ 2. Lipid Profile \\ 3. ECG
}

Criteria for Diagnosis of Myocardial Ischaemia Horizontal or down sloping ST depression of $>0.05 \mathrm{mv}(0.5$ $\mathrm{mm}$ ) in two contiguous leads suggest myocardial ischaemia. ST Segment Depression May Take One of the Following Forms

1. Horizontality of the ST Segment.

2. Upwards sloping ST segment depression.

3. Plane ST Segment depression.

4. Downwards sloping ST Segment Depression.

5. Symmetrical $\mathrm{T}$ wave inversion.

Criteria for Diagnosis of Myocardial Infarction Diagnosis of MI on ECGs is based on presence of any one of following:

- Development of new pathological Q waves 
- Presence of ST segment elevation or depression

- Development of new left bundle branch block

- The changes in ECG should be present in two contiguous leads.

\section{Statistical Analysis}

Analysis were performed by using Microsoft Excel and SPSS 20.0 version software packages.

\begin{tabular}{|ccc|}
\hline \multicolumn{3}{|c|}{ RESUL T S } \\
\hline \multicolumn{4}{|c|}{} \\
\hline Age & Frequency & Percentage \\
\hline Up to 30 Yrs. & 01 & 01.00 \\
31 yrs. -40 Yrs. & 06 & 06.00 \\
41 yrs. -50 Yrs. & 27 & 27.00 \\
51 yrs. - 60 Yrs. & 46 & 46.00 \\
> 60 Yrs. & 20 & 20.00 \\
Total & $\mathbf{1 0 0}$ & $\mathbf{1 0 0}$ \\
\hline Table 1. Distribution of Study Subjects According to Age \\
\hline
\end{tabular}

The above table 1 revels that the majority of study subjects were in age group $51-60$ yrs. (46\%) followed by $41-50$ yrs. $(27 \%)$

\begin{tabular}{|ccc|}
\hline Gender & Frequency & Percentage \\
Male & 44 & 44.00 \\
Female & 56 & 56.00 \\
Total & $\mathbf{1 0 0}$ & $\mathbf{1 0 0}$ \\
\hline Table 2. Distribution of Study Subjects According to Sex \\
\hline
\end{tabular}

The above Table 2 observed that majority of study subjects were in female (56\%).

\begin{tabular}{|ccc|}
\hline Duration of DM (years) & Frequency & Percentage \\
1 Years - 5 Years & 34 & 34.00 \\
5 Years -10 Years & 46 & 46.00 \\
> 10 Years & 20 & 20.00 \\
Total & $\mathbf{1 0 0}$ & $\mathbf{1 0 0}$ \\
\hline \multicolumn{2}{|c|}{ Table 3. Distribution of Study Subjects According to Duration of } \\
& Illness & \\
\hline
\end{tabular}

The above Table 3 observed that majority of study subjects were having DM since 5 - 10 years (46\%). The study subjects with DM > 10 years were $20 \%$.

\begin{tabular}{|ccc|}
\hline BMI & Frequency & Percentage \\
\hline Normal & 38 & 38.00 \\
Overweight & 40 & 62.00 \\
Obesity (Class I) & 22 & 22.00 \\
Total & 100 & 100 \\
\hline Table 4. Distribution of Study Subjects According to BMI \\
\hline
\end{tabular}

The above table 4 observed that majority of study subjects were overweight (40\%),

Spread of patients - scattering of DM patients according to risk factors. It was seen that a lot of patients were having dyslipidaemia (22\%). Distribution of patients according to recognitions at presentation.

The mean fasting and post prandial glucose among patients was $164 \pm 15.18 \mathrm{mg} / \mathrm{dL}$ and $189.4 \pm 23.29 \mathrm{mg} / \mathrm{dL}$ independently.

The mean LDL, HDL, VLDL, hard and fast cholesterol and greasy substances levels among patients was $118.14 \pm 24.2 \mathrm{mg}$ / dL, $42.60 \pm 5.12 \mathrm{mg} / \mathrm{dL}, 35.68 \pm 7.09 \mathrm{mg} / \mathrm{dL}, 204.96 \pm 28.76$ $\mathrm{mg} / \mathrm{dL}, 166.17 \pm 31.92 \mathrm{mg} / \mathrm{dL}$ independently.
Assignment according to ordinariness of calm MI among patients: power of calm MI among DM patients. It was seen that transcendence of calm MI among patients with DM was $27 \%$.

Catering as shown by age inescapability of calm MI among patients: It was seen that normality of calm MI among DM patients was major in age bundle 51 - 60 years (13\%) followed by age pack $>60$ years $(8 \%)$. power of calm MI among DM patients by sexual direction. It was seen that regularity of calm MI among DM patients among male patients was $12 \%$ and female was $15 \%$.

ECG changes in calm MI among DM patients. It was seen that prevailing piece of calm MI patients had ST pity with even $\mathrm{T}$ wave inversion $(77.77 \%)$ The fresh start left gathering branch block (LBBB) was seen in $11.11 \%$ patients. ECG changes suggestive of ST rise were not found.

\section{DISCUSSION}

The flow cross sectional examination was driven in the region of Western Maharashtra, Satara District to understand the ECG changes present in patients of Type 2 diabetes mellitus. In the momentum assessment, it was seen that bigger portion of patients were in 51 - 60 years age ( $46 \%$ ) trailed by $41-50$ years $(27 \%)$. In an assessment done by Sahil Gupta et al ${ }^{19}$ on assessment of ECG characteristics in patients with asymptomatic type 2 diabetes mellitus watched mean period of asymptomatic diabetic patients was $50.3 \pm 11.90$ years (age broaden 25 - 75 years). These abnormalities are more found in age 35 - 44 and 45 - 54 years. In the current assessment, it was seen that a lot of patients were female (56\%) and men were $44 \%$. It was seen that predominant some portion of patients were having DM since 5 - 10 years (46\%). The patients with $\mathrm{DM}>10$ years were $20 \%$. In an examination done by Sahil Gupta et $\mathrm{al}^{19}$ on evaluation of ECG varieties from the standard in patients with asymptomatic Type 2 diabetes mellitus viewed the asymptomatic T2DM cases with ECG changes had long haul of length of diabetes mellitus.

It was seen that a lot of patients were overweight (40\%) followed by weight Class I ( $22 \%)$. The larger some portion of patients were having dyslipidaemia (22\%). It was seen that mean fasting and post prandial glucose among patients was $164 \pm 15.18 \mathrm{mg} / \mathrm{dL}$ and $189.4 \pm 23.29 \mathrm{mg} / \mathrm{dL}$ independently. It was seen that mean LDL, HDL, VLDL, full scale cholesterol and greasy substances levels among patients was $118.14 \pm$ $24.2 \mathrm{mg} / \mathrm{dL}, 42.60 \pm 5.12 \mathrm{mg} / \mathrm{dL}, 35.68 \pm 7.09 \mathrm{mg} / \mathrm{dL}$, $204.96 \pm 28.76 \mathrm{mg} / \mathrm{dL}, 166.17 \pm 31.92 \mathrm{mg} / \mathrm{dL}$ exclusively. In an examination done by Sahil Gupta et $\mathrm{al}^{19}$ on evaluation of ECG inconsistencies in patients with asymptomatic Type 2 diabetes mellitus saw that mean fasting glucose among patients was $205 \pm 91 \mathrm{mg} / \mathrm{dL}$, mean HDL levels $39.66 \pm 10.17$ $\mathrm{mg} / \mathrm{dL}$.

In the current examination, it was seen that the inescapability of calm MI among patients with DM was $27 \%$. In an assessment done by Sahil Gupta et al $^{19}$ on appraisal of ECG varieties from the standard in patients with asymptomatic Type 2 diabetes mellitus viewed $26 \%$ asymptomatic diabetics had ECG abnormalities. Motoji Naka etal ${ }^{20}$ isolated diabetic patients and non-diabetic control subjects with respect to the regularity of calm myocardial ischaemia saw $31 \%$ astonishing nature of calm myocardial ischaemia diabetic patients. V. I. Koshlia et $\mathrm{al}^{21}$ in an evaluation on calm myocardial ischaemia 
in patients with diabetes mellitus type 2 watched power of calm myocardial ischaemia in patients with diabetes is by a wide margin higher ( 2 - 7 times) than in those without diabetes.

It was seen that power of calm MI among DM patients was major in age pack 51 - 60 years (13\%) followed by age bundle $>60$ years ( $8 \%$ ). In an assessment done by Sahil Gupta et $\mathrm{al}^{19}$ on appraisal of ECG varieties from the standard in patients with asymptomatic type 2 diabetes mellitus watched mean time of asymptomatic diabetic patients with ECG oddities $51 \pm$ 10.05 years. Motoji Naka etal ${ }^{20}$ differentiated diabetic patients and non-diabetic control subjects with respect to the normality of calm myocardial ischaemia watched mean season of patients with calm MI was 62 years.

It was seen that prevalence of calm MI among DM patients among male patients was $12 \%$ and female was $15 \%$. In an examination done by Sahil Gupta et $\mathrm{al}^{19}$ on evaluation of ECG abnormalities in patients with asymptomatic Type two Diabetes Mellitus watched female quality (53.84\%). Motoji Naka etal 20 isolated diabetic patients and non-diabetic control subjects with respect to the commonness of calm myocardial ischaemia watched female quality (38 \%) in calm myocardial ischaemia diabetic patients.

The ECG changes in calm MI among DM patients showed that bigger piece of calm MI patients had ST hopelessness and adjusted T wave inversion (77.77 \%) fresh start left pack branch block (LBBB) was seen in $11.11 \%$ patients. In an assessment done by Sahil Gupta et al 93 on evaluation of ECG varieties from the standard in patients with asymptomatic Type two Diabetes Mellitus observed most normal peculiarity viewed was ST-T changes (12\%) followed by LAE (6 \%), LVH ( $4 \%$ ), LBBB (2 \%) and RBBB (2\%). In an evaluation by Sellers $\mathrm{MB}$ et al 95 on African Americans, the collections and consistency of ECG peculiarities saw were according to the going with: surrendered QTc (25.5\%), T wave changes (22\%), LVH (18.5\%), sinus tachycardia (15.5\%), Ischaemic Heart Disease (IHD) (9\%), conduction deserts (7\%) and ectopic impacts (4 \%). ECG groupings from the standard among coherently settled diabetics were high and included conceded QTc, LVH, IHD and conduction scorns.

In other near evaluations the certainty of ECG quirks in diabetics separated from $24.9 \%-44.3 \%$ depending on the friend considered. ${ }^{22,23}$ An examination on 221 patients from Spain demonstrated that ECG eccentricities were found in 24.9 $\%$ close to the beginning and $44.3 \%$ were found around the fulfillment of the appraisal with typical term of follow up of 5.9 years. The current evaluation is cross sectional where $27 \%$ asymptomatic diabetics had ECG idiosyncrasies. In the longitudinal evaluation from Spain, the closeness of ECG irregularities could predict the occasion of future cardiovascular event in patients with T2DM more definitely than some other threat factor alone. ${ }^{24}$ The requirement of the assessment was little model size of the addressing people, follow up was not examined.

Diabetes mellitus has been known for quite a while to be connected with poor cardiovascular figure. On account of the delicate neuropathy, the coronary conductor suffering in diabetic patients is an unbelievable part of the time asymptomatic. Likewise twelve leads resting ECG can be inside standard cut off amasses even in a pushed season of coronary aratry pain. From this time forward despite the standard ECG other electrocardiographic procedures began to be secured request to locate some essential indications of myocardial harms accomplished by DM.

\section{CONCLUSIONS}

Diabetes mellitus has been known for quite a while to be connected with poor cardiovascular prognosis. Diabetes mellitus causes both microvascular and macrovascular burdens. Due to delicate neuropathy, coronary artery disease in diabetic patients is in many cases asymptomatic. In such cases, ECG can be used as an unobtrusive instrument to determine the area affected in myocardial ischaemia in asymptomatic diabetic patients.

Data sharing statement provided by the authors is available with the full text of this article at jemds.com.

Financial or other competing interests: None.

Disclosure forms provided by the authors are available with the full text of this article at jemds.com.

\section{REFERENCES}

[1] WHO Expert Committee on Prevention of Coronary Heart Disease. Prevention of coronary heart disease: report of a WHO Expert Committee, Geneva, World Health Organization, 1982.

[2] Kannel WB, Abbott RD. Incidence and prognosis of unrecognized myocardial infarction: an update on the Framingham study. New England Journal of Medicine 1984;311(18):1144-7.

[3] Pyörälä K, Epstein FH, Kornitzer M. Changing trends in coronary heart disease mortality: possible explanations. Cardiology 1985;72(1-2):5-10.

[4] Stamler J, Vaccaro 0, Neaton JD, et al. Diabetes, other risk factors and 12-yr cardiovascular mortality for men screened in the Multiple Risk Factor Intervention Trial. Diabetes Care 1993;16(2):434-4.

[5] Manson JE, Colditz GA, Stampfer MJ, et al. A prospective study of maturity-onset diabetes mellitus and risk of coronary heart disease and stroke in women. Archives of Internal Medicine 1991;151(6):1141-7.

[6] Milan Study on Atherosclerosis and Diabetes (MiSAD) Group. Prevalence of unrecognized silent myocardial ischaemia and its association with atherosclerotic risk factors in noninsulin-dependent diabetes mellitus. The American Journal of Cardiology 1997;79(2):134-9.

[7] May O, Arildsen H, Damsgaard EM, et al. Prevalence and prediction of silent ischaemia in diabetes mellitus: a population-based study. Cardiovascular Research 1997;34(1):241-7.

[8] American Diabetes Association. Consensus development conference on the diagnosis of coronary heart disease in people with diabetes: 10-11 February 1998, Miami, Florida. Diabetes Care 1998;21(9):1551-9.

[9] Puel J, Valensi P, Vanzetto G, et al. Identification of myocardial ischaemia in the diabetic patient Joint ALFEDIAM and SFC recommendations. Diabetes \& Metabolism 2004;30(3 Pt 3):3S3-3S18. 
[10] King H, Aubert RE, Herman WH. Global burden of diabetes, 1995-2025: prevalence, numerical estimates and projections. Diabetes Care 1998;21(9):1414-31.

[11] Kokot T, Nowakowska-Zajdel E, Muc-Wierzgoń M, et al. Impaired fasting glucose and silent myocardial ischaemia. Polskie Archiwum Medycyny Wewnetrznej 2005;114(5):1066-71.

[12] DeLuca AJ, Saulle LN, Aronow WS, et al. Prevalence of silent myocardial ischaemia in persons with diabetes mellitus or impaired glucose tolerance and association of hemoglobin A1c with prevalence of silent myocardial ischaemia. The American Journal of Cardiology 2005;95(12):1472-4.

[13] Stone PH. Asymptomatic myocardial ischaemia in stable angina, unstable angina, and myocardial infarction: current status and future directions. Cardiol Rounds 1998;2(7):1-8.

[14] Fornengo P, Bosio A, Epifani G, et al. Prevalence of silent myocardial ischaemia in new-onset middle-aged Type 2 diabetic patients without other cardiovascular risk factors. Diabetic Medicine 2006;23(7):775-9.

[15] Gazzaruso C, Solerte SB, De Amici E, et al. Association of the metabolic syndrome and insulin resistance with silent myocardial ischaemia in patients with type 2 diabetes mellitus. The American Journal of Cardiology 2006;97(2):236-9.

[16] Scognamiglio R, Negut C, Ramondo A, et al. Detection of coronary artery disease in asymptomatic patients with type 2 diabetes mellitus. Journal of the American College of Cardiology 2006;47(1):65-71.
[17] Jackson G, Rosen RC, Kloner RA, et al. REPORT: the Second Princeton Consensus on Sexual Dysfunction and Cardiac Risk: new guidelines for sexual medicine. The Journal of Sexual Medicine 2006;3(1):28-36.

[18] Guest TM, Ramanathan AV, Tuteur PG, et al. Myocardial injury in critically ill patients: a frequently unrecognized complication. JAMA 1995;273(24):1945-9.

[19] Gupta S, Gupta RK, Kulshrestha M, et al. Evaluation of ECG abnormalities in patients with asymptomatic type 2 diabetes mellitus. Journal of Clinical and Diagnostic Research 2017;11(4):0C39-OC41.

[20] Naka M, Hiramatsu K, Aizawa T, et al. Silent myocardial ischaemia in patients with non-insulin-dependent diabetes mellitus as judged by treadmill exercise testing and coronary angiography. American Heart Journal 1992;123(1):46-53.

[21] Koshlia VI, Martynenko A. Silent myocardial ischaemia in patients with diabetes mellitus type 2. Zaporozhye Medical Journal 2015;(6):88-92.

[22] Sellers MB, Divers J, Lu L, et al. Prevalence and determinants of electrocardiographic abnormalities in African Americans with type 2 diabetes. Journal of Epidemiology and Global Health 2014;4(4):289-96.

[23] Michael O, Ogunmola O, Tunji Y, et al. Prevalence, variants and determinants of electrocardiographic abnormalities amongst elderly Nigerians with type 2 diabetes. Journal of Medicine and Medical Sciences 2013;4(8):324-8.

[24] De Santiago, García-Lledó A, Ramos E, et al. Prognostic value of ECGs in patients with type- 2 diabetes mellitus without known cardiovascular disease. Revista Española de Cardiología (English Edition) 2007;60(10):1035-41. 